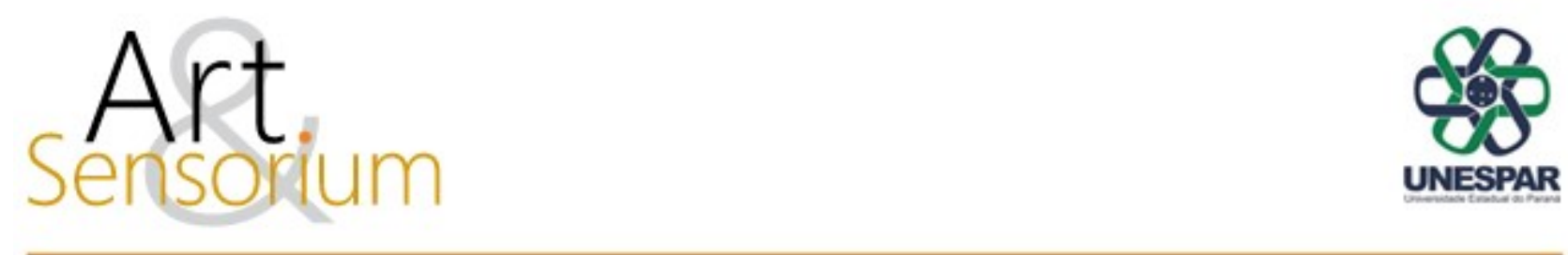

\title{
UMA DIMENSÃO SENSÍVEL NO CONTEXTO DO JORNALISMO EXPERIENCIAL
}

DOI: https://doi.org/10.33871/23580437.2021.8.2.222-236

Ricardo Uhry ${ }^{1}$

\begin{abstract}
RESUMO: Propõe-se uma reflexão preliminar sobre a dimensão sensível no contexto do jornalismo experiencial, revisando experiências pioneiras, os primeiros autores a denominarem experiencial e o impacto no jornalismo. Percorre-se a dimensão sensível a partir de práticas relacionadas ao experiencial, como o jornalismo artístico e o jornalismo estético, tentando relacionar jornalismo e artes, sob o viés de teorizações de Landowski e Uhry. Além de expor a primeira experiência documentada, refere-se a algumas prática de jornalismo experiencial, defendendo-se que os referenciais fornecem uma base para o estudo empírico da dimensão sensível do ato comunicativo salientando-se as relações que se estabelecem e que podem ser localizadas no Mapa das relações comunicativas, em que podem ser destacadas tanto questões problemáticas, quanto possibilidades experienciais que podem ter relação com experimentação e arte, entre as quais se destaca, como resultado empírico, The Learning Network, prática jornalística que pode contribuir para a evocada construção da comunicação do futuro. Conclui-se que se possa valer de diferentes possibilidades de relações comunicativas para fazer frente aos desafios do contexto dos novos tempos tecnológicos em que a dimensão sensível se destaca nas práticas jornalísticas experienciais.
\end{abstract}

Palavras-chave: ato comunicativo; dimensão sensível; jornalismo experiencial; artístico.

\section{A SENSITIVE DIMENSION IN THE CONTEXT OF EXPERIENTIAL JOURNALISM}

\begin{abstract}
We propose a preliminary reflection on the sensitive dimension in the context of experiential journalism, reviewing pioneer experiences, the first authors to call it experiential and the impact on journalism. We explore the sensitive dimension from practices related to the experiential, such as art journalism and aesthetic journalism, trying to relate journalism and arts, under the bias of Landowski's and Uhry's theorizations. In addition to exposing the first documented experience, it refers to some practices of experiential journalism, defending that the references provide a basis for the empirical study of the sensitive dimension of the communicative act, highlighting the relationships that are established and that can be located on the Map of communicative relations, where both problematic issues and experiential possibilities that may be related to experimentation and art can be highlighted, among which, as an empirical result, The Learning Network stands out, a
\end{abstract}

\footnotetext{
${ }^{1}$ Doutorando em Comunicação e Linguagens (Universidade Tuiuti do Paraná UTP), mestre (Universidade Federal do Paraná UFPR), membro do Grupo de Pesquisa INCOM Interações Comunicacionais, Imagens, Culturais Digitais, autor de Estratégias de comunicação interativa (Ed. UFPR), Serendipidade: o jogo das máscaras (UBE/Scortecci), Coordenador do Núcleo Curitiba da Universidade Rose-Croix Internacional. http://lattes.cnpq.br/9744374401387085. https://orcid.org/000-0001-6296-7258.E-mail: ricardo.uhry@utp.edu.br.
} 
journalistic practice that may contribute to the mentioned construction of the communication of the future. It is concluded that one can make use of different possibilities of communicative relations to face the challenges of the context of new technological times in which the sensitive dimension stands out in experiential journalistic practices.

Keywords: communicative act; sensitive dimension; experiential journalism; artistic.

\section{UNA DIMENSIÓN SENSIBLE EN EL CONTEXTO DE PERIODISMO EXPERIENCIAL}

RESUMEN: Se propone una reflexión preliminar sobre la dimensión sensible en el contexto del periodismo experiencial, repasando las experiencias pioneras, los primeros autores en llamarlo experiencial y el impacto en el periodismo. La dimensión sensible se recorre desde prácticas relacionadas con lo experiencial, como el periodismo de arte y el periodismo estético, tratando de relacionar el periodismo y las artes, bajo el sesgo de las teorizaciones de Landowski y Uhry. Además de exponer la primera experiencia documentada, hace referencia a algunas prácticas de periodismo vivencial, defendiendo que las referencias proporcionan una base para el estudio empírico de la dimensión sensible del acto comunicativo, destacando las relaciones que se establecen y que pueden ser localizadas en el Mapa de las relaciones comunicativas, donde se pueden destacar tanto cuestiones problemáticas, como posibilidades vivenciales que pueden estar relacionadas con la experimentación y el arte, entre las que destaca, como resultado empírico, La Red de Aprendizaje, una práctica periodística que puede contribuir a la mencionada construcción de la comunicación del futuro. Se concluye que se puede hacer uso de diferentes posibilidades de relaciones comunicativas para afrontar los retos del contexto de los nuevos tiempos tecnológicos en los que destaca la dimensión sensible en las prácticas periodísticas vivenciales.

Palabras clave: acto comunicativo; dimensión sensible; periodismo vivencial; artístico.

\section{Introdução}

Além da crise pandêmica que ainda afeta a todos, entre os tensionamentos da era digital surge um cenário disruptivo no qual tem emergido a plataformização e a desinformação, que estão relacionadas ao abuso das corporações e às notícias falsas, ao que se soma a crise do jornalismo. Crises trazem oportunidades de reinvenção de forma a contribuir para aprimorar a experiência tanto dos comunicadores quanto a fruição dos interlocutores. São alguns dos desafios que exigem criatividade para serem enfrentados, o que pode incluir inovações como o jornalismo experiencial, que é sobre o que se busca refletir enfocando sua dimensão sensível.

Propõe-se uma abordagem do ato comunicativo, refletindo-se sobre a dimensão sensível no contexto do jornalismo experiencial. Revisa-se experiências pioneiras, os primeiros autores a denominarem experiencial, e expor a primeira experiência documentada ("Harvest of Change"), do jornal The Des Moines Register. A seguir lança-se um olhar sobre a dimensão sensível, jornalismo artístico e estético e destaca-se uma prática de jornalismo experiencial (The Learning Network), do jornal The New York Times, analisada sob a teorização de Uhry (2021) e relacionada ao regime de ajustamento de Landowski (2014), além de exemplos pontuais.

\section{Jornalismo experiencial}

Um dos projetos pioneiros de jornalismo experiencial foi relatado em 17 de setembro de 2014 por DeBarros (2021): 
O jornal "The Des Moines Register" e Gannett Digital associaram-se para que se possa experienciar a história de uma família de fazendeiros de Iowa com o uso de tecnologia de realidade virtual e vídeo de 360 graus. A experiência foi lançada em "DesMoinesRegister.com" como parte da série "Harvest of Change" do "Register" sobre como as mudanças demográficas e econômicas na América estão afetando as famílias de fazendeiros de Iowa e "leva" os espectadores a um tour virtual pela fazenda da família Dammann, para uma central que inclui a casa da fazenda original de 1888 e o centro nevrálgico da operação de milho, soja da família, o que é melhor visualizado com um "Oculus Rift", de Realidade Virtual, que dá aos espectadores o que seu fabricante Oculus VR chama de uma sensação de "presença". No projeto, os espectadores podem fazer um tour imersivo e autoguiado pela fazenda, renderizado em 3-D usando o mecanismo de videogame Unity. Ao longo do caminho, há uma dúzia de segmentos de vídeo em 360 graus nos quais a família e outras pessoas que atuam na agricultura discutem seu trabalho e os problemas que enfrentam com tecnologia, culturas geneticamente modificadas, cultura em mutação e o futuro da agricultura em tempos de mudanças rápidas. Total Cinema 360, uma empresa de cinema de Nova York, filmou os vídeos usando câmeras que gravam imagens e sons em todas as direções ao mesmo tempo. O que, quando assistido pelo Oculus Rift, parece envolver o espectador, convidando a virar a cabeça (ou mover o mouse) em qualquer direção para ver o que está acontecendo ao seu redor. Há versões bidimensionais, em que se pode baixar aplicativos para PC e Mac e exige um computador veloz e placa gráfica, ou pode-se assistir a uma versão "light" em um navegador da Web depois de baixar um plug-in 3-D do Unity. Para construir a "experiência", a equipe da Gannett Digital começou com fotos e vídeos feitos na Fazenda Dammann pelo jornal Register e, depois, usaram um motor de jogo Unity para renderizar o terreno, os edifícios e a flora da fazenda. Imagens aéreas foram usadas para posicionar e dimensionar objetos com precisão. Tudo no ambiente foi construído em escala, e os edifícios e objetos incorporam texturas reais a partir de fotografias. A Total Cinema 360 filmou os segmentos de vídeo e gravou áudio, incluindo o som natural da fazenda que é ouvido na experiência (Adaptado de DeBARROS, 2021).

A propósito, no YouTube (2021) há o vídeo “Oculus Rift DK2: Harvest of Change” que permite ter uma ideia da experiência. No final de 2014, Blair (2021) relatou essa experiência imersiva, denominando-a de "jornalismo experiencial: como a Realidade Virtual pode tratar as notícias em 3D". Por outro lado, em outro trabalho pioneiro, Caetano (2015) abordou os aspectos "inteligível e sensível no processo de conversão da informação jornalística em experiência visual". E foi a partir dessas experiências pioneiras que Pavlik (2016) propôs uma "matriz do impacto da virtualidade no jornalismo", que Longhi e Caetano (2019) reelaboraram e está a seguir sintetizada:

Virtualidade: $1^{\mathrm{a}}$. etapa (adoção pré-experiencial) - produção: 2D, câmaras direcionais, microfones, edição manual, processos químicos; narrativa: linear, perspectiva em terceira pessoa, publicação/distribuição fixa; público: audiência passiva, anônima; organização: hierárquica, segura, dirigida por humanos. $2^{\mathrm{a}}$. etapa (implementação totalmente experiencial) - produção: 3D, câmeras e microfones 360, espacial, GPS, mobile, drones, ubíqua, em rede; narrativa: interativa (não linear), multissensorial (visão, toque, som), fluída ou dinâmica, personalizável, guiada por dados; público: engajado (participativo) como usuários e colaboradores, conectados, privacidade em risco; organização: conectada, participativa, guiada por dados e algoritmos, automatizada, baseada em nuvem, segurança em risco. (Adaptado de LONGHI; CAETANO, 2019, p. 84). 
Da segunda etapa do jornalismo experiencial, Longhi e Caetano (2019, p. 85-88) destacam The Islamic State, de 2014, Ebola Outbreak 360', de 2017, ambos disponíveis no YouTube; e The Displaced, Greenland is melting away, do The New York Times; De cabeça nas nuvens, Um mundo de muros, Brasil na Antártida: o continente gelado visto de cima, da Folha de S. Paulo, entre outros.

Também pode ser relacionado ao jornalismo experiencial o artigo de Pavlik (2017), em que aborda as dispositivos emergentes de mídia experiencial que permitem que as pessoas com deficiências se envolvam cada vez mais em ambientes de aprendizagem móveis e interativos personalizáveis, interativos, envolventes e multissensoriais. $\mathrm{O}$ autor delineia a natureza e os parâmetros da mídia experiencial e suas implicações para a aprendizagem de pessoas com deficiências. A articulação de um modelo de mídia experiencial estabelece as bases para investigações futuras. Como uma estrutura preliminar para testar este modelo de mídia experiencial, Pavlik pesquisou pessoas com deficiência que participaram de protótipos de mídia imersiva, multissensorial e interativa, o que é reexaminado no contexto do recente desenvolvimento de dispositivos de realidade virtual disponíveis comercialmente, que são Google Cardboard, Samsung Gear VR e Oculus Rift. E Pavlik (2017), conclui que há uma estrutura para avaliar a eficácia potencial das dispositivos emergentes de mídia experimental para a aprendizagem entre usuários com habilidades diferentes (PAVLIK, 2017).

Também, para Pavlik (2019a), o jornalismo e o conteúdo da mídia se baseiam na narrativa. Moldar essa narrativa está relacionado à qualidade do meio de entrega de conteúdo e à natureza do engajamento público. Com o desenvolvimento da mídia digital em rede, o papel do público está se transformando para se tornar cada vez mais a de um usuário ativo que vivencia as histórias como um participante, em vez de um receptor passivo de conteúdo. O autor propõe um novo modelo de mídia experiencial baseado em seis qualidades primárias do ambiente digital, que são 1) interatividade, 2) imersão, 3) apresentação multissensorial, 4) algorítmica e orientada por dados, 5) perspectiva de primeira pessoa e 6) uma interface de usuário natural. A realidade aumentada e a realidade virtual estão entre as formas de mídia experiencial mais amplamente discutidas, e incluem, por exemplo, vídeo avançado de ultra alta definição. A mídia experiencial traz implicações para a natureza, produção, impacto e o futuro da narrativa mediada (PAVLIK, 2019a).

Pavlik (2019b) examina a natureza, os parâmetros e as consequências da realidade virtual, realidade aumentada e outras mídias experienciais no jornalismo, especialmente o conteúdo das notícias. Em função dos avanços nas dispositivos de tecnologia, as notícias experienciais apresentam uma oportunidade de envolver um público cada vez mais fragmentado, além de apresentar as implicações práticas, éticas e políticas para aqueles que criam as notícias, bem como para aqueles que consomem ou interagem com esse conteúdo. $O$ autor propõe uma estrutura conceitual para compreender criticamente a evolução das notícias, focando a análise na experiência do usuário, que está cada vez mais interativa, multissensorial e envolvente (PAVLIK, 2019b).

Pavlik (2019b) traça um guia para a excelência jornalística em notícias experienciais: 1) situa a natureza mutante do jornalismo contemporâneo em um contexto histórico, argumentando que estamos entrando em uma terceira era de conteúdo de notícias ou histórias jornalísticas; 2) discute a natureza do design e um conjunto de seis princípios e práticas que os jornalistas podem empregar na criação de conteúdo de notícias experienciais de qualidade, que podem envolver melhor o público de notícias em evolução; 3 ) enfoca a experiência do usuário de notícias. A natureza multissensorial, interativa e imersiva dessa experiência é mais evidente na realidade aumentada e na realidade virtual. É cada vez mais uma parte de outras formas de mídia emergentes, incluindo dispositivos de áudio interativos, vídeo de ultra alta definição e dispositivos de mídia baseadas em dados e inteligência artificial; 4) examina a natureza codificada das notícias experienciais. Geolocalização, dados e algoritmos sinalizam uma mudança fundamental nas formas como o conteúdo de notícias não é apenas entregue, mas também acessado e engajado pelo público (PAVLIK, 2019b). 
Em síntese, Longhi e Caetano (2019) apontam que o jornalismo experiencial seria o que incrementa as relações afetivas em relação a certos tipos de notícias, seja pela experimentação buscada no fazer jornalístico, seja pela "experiência do leitor/usuário enquanto fruidor de conteúdos". Da análise dos jornais Folha de S. Paulo, The New York e The Guardian, as autoras sugerem "que se manifesta uma instância na produção e fruição de conteúdos jornalísticos que podemos definir como valorexperiência" (LONGHI; CAETANO, 2019). E o "valor-experiência" seria o fator distintivo do jornalismo experiencial.

\section{Uma dimensão sensível nas relações comunicativas}

Apresentados os antecedentes sobre uma abordagem experiencial, e referido a práticas relacionadas, passamos a sintetizar uma teorização que inclua a dimensão sensível e nos permita analisar as práticas. Considerando o mapa de Martín-Barbero (2003, p. 11-21) e principalmente a partir de visão geral das relações de comunicação, que indica os atores, as formas de atuação e relações, Uhry propôs a teoria das relações comunicativas na forma de um Mapa das relações comunicativas dos diferentes territórios da comunicação, com dois eixos relacionais: $1 .^{\circ}$ Integração de forma mediada: que permite relacionar o aspecto Social (o quê e o porquê?) com as mudanças sofridas em direção à predominância do Mercadológico (como?), este mais na perspectiva dos gestores da comunicação, o que envolve a gestão integrada da comunicação e a adequação dos formatos culturais e industriais às conveniências do mercado. 2. ${ }^{\circ}$ Mediação de forma a integrar: relaciona os atores sociais e analisa as lógicas de produção dos Comunicadores (quem?) e as competências de recepção dos Públicos (a quem?).

Os eixos relacionais fazem referência aos sistemas de mediação serem modelos de integração devido ao encontro dos eixos "Integração de forma a mediar" e "Mediação de forma a integrar" e, com as quatro perspectivas, compõem o Mapa das relações comunicativas. Assim exatamente no quadrante central do Mapa das relações comunicativas, em que os eixos relacionais, que indicam as ações de integrar e de mediar se entrecruzam, é onde localizamos as forças macro ambientais "político-legais, econômicas (e tecnológicas), culturais" (WRIGHT, KROLL, PARNEL, 2000, p. 47-59), ao que se soma a dimensão sensível; e que tem certa semelhança - e é complementado - com o sistema social de Parsons sintetizado e adaptado de Habermas (2003b, p. 334-442): político (normas), econômico (recursos), cultura (valores) e personalidade (simbólico); e ainda se propõe relacionar às lógicas e aos regimes de interação semiótica de Landowski (2014): regularidade (programação), intencionalidade (manipulação), aleatoriedade (acidente) e sensível (ajustamento), como segue: Político (metas) e legal, que envolve o subsistema de integração (normas) e atingimento dos fins e pode ser relacionado à lógica de regularidade e ao regime de interação de programação; Econômico, que engloba o subsistema de adaptação (meios tecnológicos) e comportamento (recursos) e pode ser relacionado à lógica de aleatoriedade e ao regime de interação de risco; Cultural, que abrange o sistema de manutenção de padrões culturais e estruturas (valores) e pode ser relacionado à lógica de intencionalidade e o regime de interação de manipulação; Sensível que envolve "um subsistema de personalidade", a vida simbolicamente estruturada para atingir fins, desempenhar papéis, o que pode ser relacionado à lógica de sensibilidade e ao regime de interação de ajustamento.

De tal forma, buscando localizar as relações comunicativas, Uhry (2021) propôs teorização a partir das perspectivas de análise sintetizadas na Figura 1, em que as setas indicam relações comunicativas em todas as direções (e sugerem feedback) e compõem a teoria das relações comunicativas que se estabelecem na comunicação na sociedade, na forma de um Mapa em que se indica os dois eixos relacionais (mediar e integrar) com contrafluxos em sentido inverso (contra hegemônicos), as ligações, interfaces, articulações e confrontos entre atores sociais, categorias sociológicas, forças macroambientais, disciplinas, especialidades, formas de comunicar e outras conexões possíveis que sugerem a complexidade. 
É algo complexo que se dá por meio da transversalidade comunicacional entre as dimensões, perspectivas, lógicas e atores sociais, sugerindo-se eliminar fronteiras rígidas e havendo comunicação e retroalimentação (feedback) contínuos comunicante em todas as direções. O modelo relacional não se pretende fixo, imutável, mas, pelo contrário, cada perspectiva ou setor ou termo pode ser comunicante com outros, como em um fluxo em que há imbricamento e, por momentos, as perspectivas podem confundir-se.

A propósito da transversalidade, o modelo indica o fluxo integrar do social ao mercadológico, mas pode haver contrafluxo comunicacional, ou seja, fluxo contra-hegemônico, no sentido inverso do mercadológico, de forma a reafirmar os valores socioculturais, em vez do consumismo mercadológico. Igualmente dos públicos pode haver contrafluxo contra o mediar de forma a integrar, invertendo-se a direção, com o público se assumindo comunicador alternativo e invertendo o sentido do integrar para assumir uma postura cidadã responsável. Com tal teorização que se quer flexível, passa-se a examinar a comunicação na sociedade sob as seguintes perspectivas de análise:

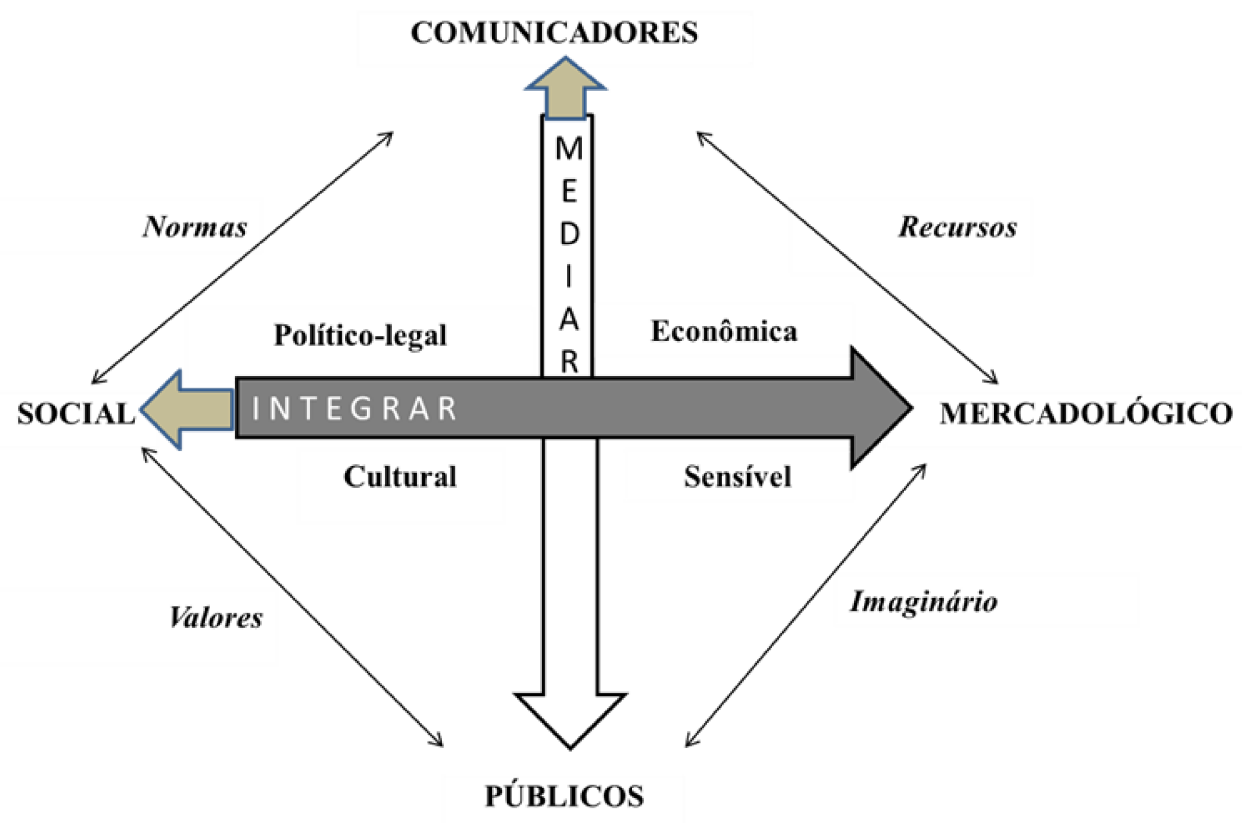

Figura 1: Mapa das relações comunicativas. Fonte: Uhry (2021).

1) Social: foco em o que se atua no social (estratégia ou forma) e em o porquê, objetivo ou efeito social a ser comunicado, em que, no seu eixo no sentido da perspectiva Mercadológica (tipos e produtos culturais), está relacionado à adequação dos formatos culturais às conveniências comerciais, ou seja, a industrialização da cultura para fins de consumo dos Públicos e o percurso da comunicação. E, do Social em direção aos Públicos, envolve os aspectos macro ambientais culturais e os valores, que estão conectados a manter estruturas e padrões culturais e está relacionado à lógica intencional e às relações interativas manipulativas. E do Social aos Comunicadores envolve os aspectos políticolegais e o subsistema integrador, das normas, e está relacionado à lógica de regularidade e às relações interativas de programação.

2) Comunicadores: quem é que produz a comunicação, as competências comunicativas, o controle social, as ideologias profissionais e rotinas produtivas e está relacionado com os Públicos, que são cidadãos, consumidores e outros. E, dos Comunicadores em seu eixo no sentido Social, considera forças macro ambientais político-legais e as normas (leis) que têm ligação com a integração e envolve a lógica da regularidade e as relações de programação. Dos Comunicadores ao Mercadológico envolve a dimensão econômica e os recursos e pode ser relacionado à lógica de aleatoriedade e às relações interativas de risco. 
3) Públicos: para quem? Consumidores e/ou cidadãos e outros e envolve questões de recepção e, no sentido à perspectiva Mercadológica, envolve vida simbólica em função de obtenção dos fins, desempenho de papéis e o subsistema personalidade, relaciona-se ao imaginário, ao sensível, e envolve a lógica da sensibilidade e as relações interativas de ajustamento. E dos Públicos em direção ao Social, envolve aspectos culturais e os valores e pode ser relacionado à lógica de intencionalidade e ao regime de interação de manipulação.

4) Mercadológico: como, que envolve a gestão estratégica da comunicação integrada, as forças macro ambientais econômicas e, em direção ao eixo Comunicadores, está relacionado às forças econômicas, aos recursos e envolve a lógica de aleatoriedade e as relações de interação de risco. E o Mercadológico tem ligação com a perspectiva dos Públicos e com as tecnologias do imaginário e do sensível pode ser relacionado à lógica da sensibilidade e às relações interativas de ajustamento.

\section{Uma dimensão sensível no jornalismo experiencial}

Tendo apresentado a teorização de Uhry (2021) na qual há uma dimensão sensível e que envolve também a de Landowski (2014), focamos agora especificamente a dimensão sensível no contexto do jornalismo experiencial, e inovações como o jornalismo artístico e o jornalismo estético que podem ser relacionadas ao ato comunicativo.

Sintetizando, Landowski (2017, p. 200) destaca aspectos como "abertura em direção à inteligibilidade do sensível" e "problemática da presença e da produção do sentido em ato" levou a elaborar uma proposta de um "modelo interacional ampliado em função da pluralidade dos regimes de sentido", a teoria que foi concebido "para tempos de crise", sendo primeiramente esboçado em Landowski (2017b) e sistematizado em Landowski (2014), na forma de uma teorização em macro perspectiva sociossemiótica que consta de quatro regimes de interação e lógicas respectivas:

I. Acidente (risco), fundado na lógica da aleatoriedade, na probabilidade mítica ou matemática, relacionado à descontinuidade e ao "fazer sobrevir".

II. Manipulação (estratégia), fundada na lógica da intencionalidade, na motivação consensual ou decisória, relacionada à não-descontinuidade e ao "fazer querer".

III. Programação (regularidade), fundada na lógica da regularidade causal ou simbólica, relacionada à continuidade e ao "fazer advir".

IV. Ajustamento (sensibilidade), fundado na lógica da sensibilidade perceptiva ou reativa, relacionado à não-continuidade e ao "fazer sentir" (Adaptado de LANDWSKI, 2014, p. 80).

$\mathrm{Na}$ apresentação de seu modelo, Landowski (2014) traz alguns exemplos que evidenciam a operacionalidade do modelo e permitem pistas de como se pesquisar empiricamente os diferentes regimes de interação. Também traz sugestões de que cada um dos regimes teria que ser analisado a partir de atos comunicacionais (LANDOWSKI, 2014, p. 85). É o que torna possível incluir análise também sob uma abordagem empírica sob a ótica do modelo de Landowski, que se refere, por exemplo, ao ajustamento como um modo vinculativo de interação de um e outro poderem se realizar mutuamente (accomplissement, no original), criando uma relação interativa gratificante (LANDOWSKI, 2014, p. 52-54).

Do que se destaca a lógica de sensibilidade e o regime de interação de ajustamento proposto por Landowski (2014): a "interação por ajustamento" tem amplas perspectivas de "criação de sentido" por oferecer experiência e conhecimento intuitivo. Ajustamento refere-se a que, na interação, "cada um dos participantes encontra" e "sente na maneira de agir" do outro "que os princípios da interação emergem pouco a pouco", o que se dá pelo "contato" contagioso, em que os participantes da interação "coordenam suas dinâmicas" relacionais "por meio de um fazer conjunto" que envolve "sentir reciprocamente", uma "competência estésica" de sujeitos "dotados, ademais, de um corpo e, por isso 
mesmo, de uma sensibilidade", o "fazer sentir", um contágio entre sensibilidades" (LANDOWSKI, 2014, p. 47).

Assim trata-se o ajustamento de uma interação na "qual nem o sentido nem o valor, nem as condições" em que possam aparecer "estão fixados de antemão, mas no qual eles se criam no ato, em função da disponibilidade" dos participantes "um face ao outro" " (LANDOWSKI, 2017, p. 21).

E, ao referir-se ao sensível, Landowski (2014, p. 51-52) identifica duas formas: sensibilidade perceptiva que "nos permite não apenas experimentar pelos sentidos as variações perceptíveis do mundo exterior", que estão ligadas aos outros e ao mundo, mas as "internas que afetam" o próprio corpo e "sensações diferenciadas que fazem por si mesmo sentido"; sensibilidade reativa que é o que "atribuímos, por exemplo, aos toques do teclado de um computador ou um pedal de acelerador" quando os consideramos "sensíveis", coisas com que se interage "só pelo prazer", constituindo-se "relações e ajustamento gratificantes", que geram sentido e "valor numa mútua realização (accomplissement) de si".

A propósito, Greimas (2017) denomina um capítulo de sua última obra "Da imperfeição" de "imanência do sensível" ao comentar e analisar textos tocantes em que apresenta "fratura[s] na vida" dos personagens, na forma de eventos únicos, extraordinários, que deixam "o ressaibo da imperfeição" do sensível, por meio da "transformação fundamental da relação entre o sujeito e objeto", estabelecendo-se um "novo estado de coisas". E registra que "A coalescência das sensações pode ser considerada um enriquecimento da comunicação." (GREIMAS, 2017, p. 77-82). Um dos textos analisados é "O guizo", em que relata que o senhor Palomar (I. Calvino) passeia na praia e se depara com uma jovem deitada na areia a tomar sol com os seios nus, o que provoca um sobressalto experiencial, a que denomina "isotopia da visualidade pela tatilidade", um "fascinação do objeto" pelo deslumbramento dos olhos (GREIMAS, 2017, p. 39-46).

"A distinção entre uma grande estética, das fraturas, e as escapatórias empreendidas por Greimas" é o que Caetano e Fischer (2014, p. 189) destacam, ao se referirem a "dimensão sensível no comunicacional", do que destacam as "interações contagiantes das redes (não apenas virtuais)," as "coisas (objetos e máquinas) na vida cotidiana e sua condição sensível a outras coisas e seres humanos" e, ao confluir "objetos e olhares, percebemos o ajustamento que foi se forjando".

Assim, apresentada a dimensão sensível, passamos a abordar o jornalismo artístico e o jornalismo estético, inovações que poderiam ser relacionadas ao sensível. Mesmo considerando que vivemos em um contexto de mudança de valores, práticas e arranjos do trabalho, pode-se supor que há convergências entre jornalismo e arte. Ao pesquisar essas profissões em aparente conflito e considerando ideologias e discursos, pode-se supor que permanecem controversas e complexas. Assim, por meio de uma análise hermenêutica crítica, Postema e Deuze (2021) destacam áreas de tensionamento na confluência de jornalismo e artes e argumentam que o jornalismo sempre esteve entrelaçado com as artes, o que não se limita às democracias ocidentais.

Os autores propõem um continuum por meio de um modelo teórico para mapeamento e percepção da coexistência de abordagens artísticas e jornalísticas de notícias que funcionem. O continuum de "artes e jornalismo" oferece uma dimensão frutífera de estudar o trabalho jornalístico como uma forma da prática artística em uma variedade de contextos. Em conclusão, é proposta uma consideração do "jornalismo artístico" como forma de profissão para articular sua base criativa com seu objetivo de perseguir a verdade, incluindo as motivações intrínsecas e afetivas de seus praticantes (POSTEMA; DEUZE, 2021, p. 1), o que pode ser relacionado à dimensão sensível.

Como campo de prática o jornalismo é semelhante a outras indústrias criativas e o mundo da arte. As sociedades democráticas consideram ambos cruciais e são vistos como "métodos culturais para formar a consciência" (ADAM, 2006, p. 365). Na atualidade jornalismo e artes enfrentam desafios semelhantes. Jornalistas e artistas operam em condições de trabalho precárias, compartilham aspectos 
intrínsecos e afetivos, motivações de trabalho semelhantes e, até certo ponto, desenvolvem ética e epistemologias relativas ao dizer a verdade e à arte. Ambos também encontraram desafios econômicos e tecnológicos disruptivos nas últimas décadas, durante os quais os papéis dos profissionais mudaram e a participação do público se normalizou (POSTEMA; DEUZE, 2021, p. 1).

Por sua vez, Adam (2006, p. 367) refere-se a uma abordagem artística: “[...] como o jornalismo é ensinado, ele deve ser banhado na luz da imaginação e na ideia de que o jornalismo pode ser e muitas vezes é uma de nossas artes mais importantes." No entanto, há um viés de "jornalismo artístico" e "jornalismo cultural" que são quando jornalistas cobrem artes e cultura, embora se trate mais de divulgação das artes e da cultura. O que é possível constatar nos sábados e domingos nos jornais $\mathrm{O}$ Estado de S. Paulo e Folha de S. Paulo.

A questão que Postema e Deuze (2021) colocam é como o jornalismo, considerado forma de arte, pode ir além de uma relação dicotômica entre jornalismo e artes? Um continuum de artes e jornalismo é vital para compreender o que está acontecendo no trabalho jornalístico contemporâneo. Nesta concepção, as artes são poesia, literatura, teatro, filme, videogames, quadrinhos, fotografia, pintura, escultura, design, arquitetura, música e dança. Os gêneros de jornalismo considerados "estabelecidos" são o cinema (incluindo documentário, tv, rádio), fotografia (fotojornalismo), design (gráficos de notícias) e literatura (jornalismo literário). O ponto de partida é o jornalismo, pois com o termo "jornalismo artístico" a arte se torna o modificador do jornalismo, enfatizando sua relação com os estudos e a prática do jornalismo (POSTEMA; DEUZE, 2021, p. 2-3).

Postema e Deuze (2021) destacam como o desenvolvimento centrados em fatos, do jornalismo angloamericano, influenciou a atitude da indústria de notícias em relação ao trabalho artístico. A noção de jornalismo conjugado com as artes é desvendada por meio de um exame de confluência de formas, valores e práticas. Os autores examinam os extremos do jornalismo em suas formas artísticas e descrevem práticas que podem ser identificadas como artísticas e jornalística, com a fotografia jornalística, concluindo que:

Em suma, no espectro das artes e do jornalismo, as formas de notícias podem ser identificadas entre os extremos de uma notícia direta, prática e de estilo simples e experiências de arte estimulantes, multissensoriais, evocando vários graus de resposta (emocional) em direção a coexistência de sensíveis e factuais verdades [towards coexisting factual and felt truths, no original. Tradução nossa]. (POSTEMA; DEUZE, 2021, p. 7).

Para Postema e Deuze (2021, p. 10), os valores estéticos - a dimensão sensível - e os valores jornalísticos não devem ser percebidos como dicotomias, mas ser abordadas como extremos de um mesmo espectro: de um lado, os "fatos são sagrados" e, de outro lado, um purista "art pour l'art". A partir do que propõem um continuum, o jornalismo artístico concebido como um conjunto deliberado de práticas, movendo-se - como pontos individuais em uma variedade de tons e tons - entre os ideais do jornalista absoluto e do puro artista, entre extremos orientados por fatos e dirigidos por afetos, e entre "fatos reais" e valores "art pour l 'art".

Na concepção de Postema e Deuze (2021, p. 11-12), o jornalismo como prática artística leva o jornalismo de volta às suas raízes, em uma confluência de gêneros artísticos (pintura, design gráfico, poesia, literatura, fotografia, filme, jogos, quadrinhos, teatro, arquitetura, música e dança) que sempre fizeram parte do noticiário. As produções e serviços apreciados e premiados como artísticos e jornalísticos indicam que o trabalho artístico e a produção devem ser considerados constitutivos da indústria de notícias. As dispositivos por meio das quais a produção e as atividades jornalísticas são produzidas e distribuídas requerem uma abordagem mais artística do jornalismo. No continuum 
proposto pelos autores as formas de notícias podem ser identificadas entre os extremos de um resumo de notícias prático e simples e uma experiência de arte estimulante multissensorial, entre evidências verificáveis (fatos) e envolvimento sincero (afeto), evocando vários graus de resposta (emocional) no sentido de coexistir factual e sensíveis verdades. No continuum, os gêneros tão díspares quanto jornalismo narrativo, produção de documentários, fotojornalismo e design gráfico de notícias podem mover-se entre verdades factuais e sensíveis; entre os "fatos sagrados", o discurso do jornalista inexistente que, como um observador distante, relata "nada além dos fatos", e o discurso "art pour l'art" do artista inexistente para quem nada conta além do valor intrínseco das artes. O continuum das artes e do jornalismo compreende as práticas envolvidas em uma busca de informações precisas sobre eventos recentes e sua apresentação estética original e deliberada em qualquer forma sensorial, para edificação pública e ressonância emocional (POSTEMA; DEUZE, 2021, p. 11-12).

Nossa sugestão é de que a proposta do continuum arte e jornalismo (POSTEMA; DEUZE, 2021) esteja relacionada com a dimensão sensível do jornalismo experiencial. Outra prática que pode ser considerada experiencial surge da indagação se o jornalismo pode ser relacionado propriamente com arte. Cramerotti (2009) trata de uma "virada jornalística" no mundo da arte no sentido de, ao invés de buscar operacionalizar o que seria um jornalismo artístico, abordar o "jornalismo estético", o que se dá a partir das "práticas artísticas na forma de investigação de circunstâncias sociais, culturais ou políticas" e, nas pesquisas, destacar os resultados que "tomam forma no contexto da arte e não por meio dos canais de mídia” (CRAMEROTTI, 2009, cap. 2).

Em tal concepção, os meios tradicionais concentram-se nas informações que são produzidas, distribuídas e absorvidas por meio dos aparatos convencionais, ao que Cramerotti (2009) denomina "informing". Na tentativa de construir uma alternativa ("how to inform without informing", o subtítulo da obra), a arte tende a usar métodos investigativos e de testemunhar e dispor de mais tempo para obter um certo conhecimento mais sensível sobre um problema, situação, narrativa individual ou histórica, aproximando-se da dimensão estética do jornalismo. E, em tal concepção, o jornalismo torna-se o fator modificador da arte, pois, embora procure o jornalismo, seu foco principal parece estar nos artistas que atuam como investigadores, testemunhas e mergulham subjetivamente na questão a ser narrada (CRAMEROTTI, 2009), o que sugerir aproximação com a dimensão sensível do jornalismo experiencial.

\section{Considerações preliminares}

Refletindo sob tais aspectos, pode-se considerar que o ato comunicativo tem uma dimensão sensível no contexto do jornalismo experiencial, do qual foram destacados aspectos artísticos e estético do jornalismo. E, das práticas do jornalismo experiencial, refere-se a "Expedição Antártida" do jornal Estado de S. Paulo (2021), que é como se estivesse experimentando um voo e além de ver a Ilha Rei George (Antártida), aparece a informação de que "Você está sobrevoando a Ilha Rei George, na Antártida." No experiencial proposto pelo jornal, está-se convidando o leitor a sair das formas tradicionais e - com a tecnologia - ajustar-se a uma experiência virtual em que lhe é proporcionada a experiência sensível que se sugere possa ser similar a que estivesse chegando pelos ares a Ilha Rei George, na Antártida, o local a lhe ser apresentado no ato comunicativo.

Do exposto, sintetizando, o ponto de partida foram as abordagens de Uhry (2021), da teoria das relações comunicativas na forma de um mapa com o qual se pode analisar, localizar e percorrer os diferentes territórios da comunicação, propondo-se a examinar as perspectivas Social, Mercadológica, Comunicadores e Públicos e demais questões envolvidas, que é complementada por os regimes semióticos de interação, de Landowski (2014). E buscamos alguma articulação com situações ou casos empíricos, verificando se há possibilidades experienciais de verificação da operacionalidade das teorizações que possibilitam estabelecer correlação com experimentação e a 
arte, por exemplo, o que se sugere possa contribuir para um construção de futuro para a comunicação, pela formação de leitores críticos e pela experimentação educativa, informativa e artística.

Um exemplo empírico de possibilidades comunicacionais relacionadas com ações experienciais é o seguinte, indicando-se as relações comunicativas: a rede de aprendizado ("The Learning Network") do jornal norte-americano "The New York Times" (2021) criou o educativo Mentoria de Textos ("Mentor Texts"), com o objetivo de ensinar a escrita que é praticada no Times, desmistificar para os estudantes as técnicas criativas que os jornalistas usavam para encantar, oferecer exercícios para encorajar os estudantes a experimentar essas mesmas técnicas nas próprias produções, o que envolve, por exemplo, aprender a refletir sobre uma experiência pessoal, como parafrasear uma investigação, como explicar a importância de um tema e como incluir detalhes sensíveis ao criar um argumento. Evidencia-se ação educacional e, ao mesmo tempo, a prática de experimentação, o que envolve responsabilidade social do Times.

Quanto às possíveis relações complexas que se estabelecem, $1^{\circ}$. Os indivíduos que compõem o coletivo de atores sociais "Comunicadores" do Times mantêm uma relação comercial com indivíduos que compõem o coletivo de atores sociais "Públicos", especificamente consumidores leitores jovens, e divulga os serviços "The Learning Network", colocados à disposição no mercado consumidor jovem do Times em uma determinada sociedade (norte-americana), uma vez que $2^{\circ}$. os "Comunicadores" têm amparo legal, fruto de relação social que mantêm com os governos e que os autorizam a desencadear $3^{\circ}$. uma relação mediada de comunicação visando atingir os "Públicos" para divulgar ensinamentos de escrita sob mentoria, procurando persuadi-los a participarmos da experiência situada na perspectiva "Social", para que venhamos a experimentar e desenvolver habilidades redacionais $4^{\circ}$. O que, no fundo, envolve propósito comercial proposto pelos indivíduos que compõem o coletivo de atores sociais do "Mercadológico" do Times e 5'. Que, no fundo, é uma forma implícita de relacionamento comercial, de forma a virem os jovens leitores a se $6^{\circ}$. Integrarem (relação comercial) aos leitores do jornal, podendo os indivíduos jovens que compõem o coletivo de atores sociais "Social" integrar-se ao coletivo de atores sociais do "Mercadológico" como consumidores do Times (adaptado de UHRY, 2021), o que pode ser relacionado com o "regime de interação de ajustamento" por ser baseado na sensibilidade, no "fazer sentir" (Landowski, 2014, p. $80)$.

Trata-se de uma experiência que permite passar do regime da programação jornalística ao regime de interação de ajustamento, que afeta a sensibilidade perceptiva e reativa do experimentador do ato comunicativo e pode trazer "l'accomplissement" - a realização de ambos, o experimentador e os criadores do jornalismo experiencial. Assim, do exposto, para focar empiricamente o jornalismo experiencial, escolhemos partir de uma macro perspectiva sociossemiótica, proposta Landowski (2014), que consta de quatro regimes de interação como já apresentado.

Do que se destaca o regime de interação ajustamento, fundado na sensibilidade, em que o regime de sentido consiste em "fazer sentido" e o regime de risco caracteriza-se pela "insegurança", relacionados à sensibilidade perceptiva e à sensibilidade reativa, que é o que pode ser relacionado ao ato comunicativo da dimensão do "fazer fazer", ao "fazer sentir" e à dimensão sensível no jornalismo experiencial como exemplificado com a experiência de "The Learning Network" de "The New York Times" e referido à "Expedição Antártida" do Estadão.

$\mathrm{Na}$ apresentação de seu modelo, Landowski (2014) traz alguns exemplos de comediantes, políticos e um policial, o que permite pistas de como se pesquisar empiricamente o jornalismo em sua dimensão sensível. Também traz sugestões de que cada um dos regimes teria que ser analisado a partir de atos comunicativos (LANDOWSKI, 2014, p. 85) como os apresentados, o que torna possível a abordagem empírica sob a ótica do modelo de Landowski, que se refere ao ajustamento como a melhor maneira de um e outro poderem se realizar mutuamente (accomplissement, no original), criando uma relação 
gratificante (LANDOWSKI, 2014, p. 52-54), tanto para a produção do jornalismo, quando a sua fruição, o que pode ser considerado jornalismo experiencial em sua dimensão sensível.

É um desafio a ser pesquisado, inicialmente debruçando-se sobre jornais em busca da dimensão sensível, o jornalismo experiencial artístico. Outra possibilidade que pode ser considerada como jornalismo artístico é "A arte nos sonha", de Carlos Netto (2021), em que a música se torna "revelação e inspiração do ser" e em que se concilia um livro com artigos de longo formativo (que podem ser considerados jornalísticos) e um site "http://aartenossonha.com.br" em que estão as músicas que devem ser escutadas junto com as propostas textuais que poderiam caracterizar uma proposta de jornalismo artístico.

Outra proposição de jornalismo artístico é do jornal A Folha de São Paulo em sua edição de 5 junho 2021, "Seminário Folha meio ambiente", em que são apresentadas fotos em preto e branco de Lalo de Almeida sobre a área devastada em terra indígena Bacajá (PA), em que fíca evidente que o fogo deixa cicatrizes profundas na floresta. É uma imagem de grande impacto e em que se concilia foto e texto com uma força artística expressiva. É uma força artística que é destacado por Rancière (2021, p. 275): "Se a fotografia e o texto são independentes é porque ambos têm vocação a dizer tudo", ao defender que "aisthesis designa o modo de experiência a partir do qual, há dois séculos, reconhecemos como pertencente à arte" (RANCIÈRE, 2021, p. 7).

\section{Conclusões}

Do exposto, destacam-se aspectos relacionados à dimensão sensível do jornalismo experiencial artístico que vêm apresentando uma combinação de tecnologia e de criatividade, do que se propõe a possibilidade de se vislumbrar aspectos como participação dos públicos, experimentação gratificante, desenvolvimento da sensibilidade e do gosto estético dos leitores. E em que se busca incrementar as relações afetivas em relação às notícias, seja pela experimentação inovadora buscada no fazer jornalístico, seja pela experiência estética ou artística proporcionada ao leitor enquanto fruidor de experiência jornalística sensível, envolvente e enriquecedora.

O jornalismo experiencial artístico pode contribuir para a realização ao aprimorar a experiência tanto dos comunicadores quanto a fruição dos interlocutores. Também podemos considerar outras possibilidades como tecnologias digitais, robôs jornalistas, algoritmos e outras inovações que também podem ser relacionadas ao sensível, como apresentado por Uhry e Caetano (2021). O desafio é desenvolver a capacidade para sentir o problema da perspectiva do outro, desenvolver a sensibilidade e melhor situar os conflitos da realidade. Eis-nos diante da possibilidade de avançar nas pesquisa da dimensão sensível do jornalismo experiencial artístico.

Assim, na figura 2 a seguir apresentam-se sinteticamente algumas relações que se podem ser localizadas como análises no Mapa das relações comunicativas: (i) Estado de S. Paulo com normas informativas sobre Antártida e experiencial de vivenciar a chegar pelos ares; (ii) rede de aprendizado (The New York Times) relacionado com dimensão sensível do imaginário experimental e educativa; (iii) A arte nos sonha com valores artísticos; (iv) Folha de S. Paulo com recursos educativos e artísticos sobre o meio ambiente. 


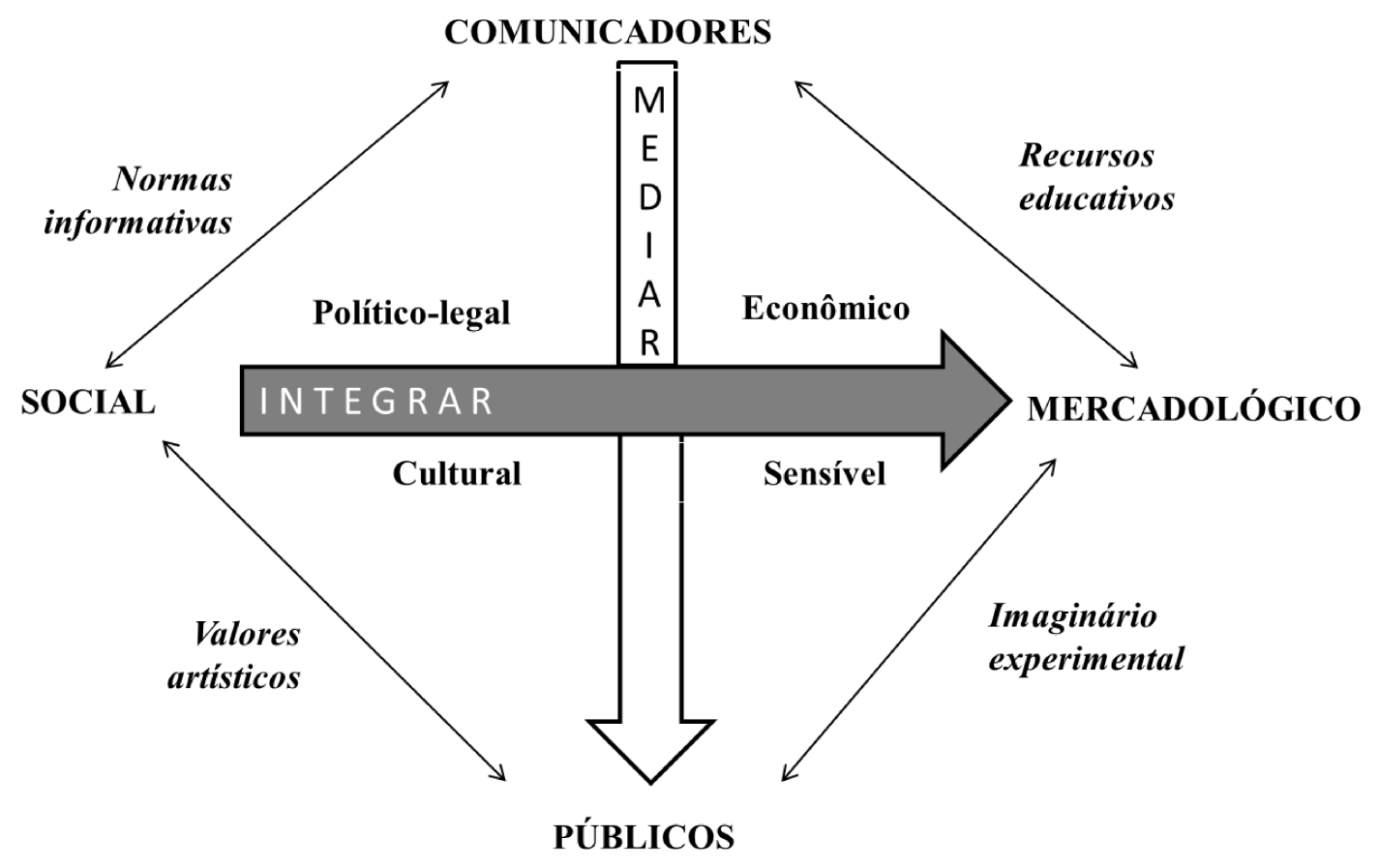

Figura 2: Análise no Mapa das relações comunicativas. Fonte: adaptado de Uhry (2021).

Do exposto, conclui-se que os exemplos empíricos que guiaram nosso raciocínio reflexivo permitem relação entre comunicação, arte e experimentação, destacando o caso da rede de aprendizado, de The New York Times, com valores espiritualistas com relação à dimensão sensível do imaginário experimental e tentativa de fomento à experienciação do usuário, o que pode ser considerada possibilidade experimental do periódicos à experienciar o outro (PAVLIK, 2019) na relação comunicativa, os quais foram apresentados no contexto de meios de comunicação, e que sugerem possibilidades para além de elencar problemas comunicacionais e propor alternativas.

Assim, foi possível articular e repensar teorizações tradicionais para uma proposta teórica das relações comunicativas, sugerindo laços complexos entre jornalismo experimentação e arte, que podem ser considerados no quadro de uma cartografia dos possíveis para a constituição de alternativas para a construção da comunicação do futuro.

Finalmente, retomando o exposto em Uhry e Caetano (2021), ao mesmo tempo que há crise na comunicação, evidencia-se que há oportunidades para a reinvenção: (i) inovar jornalisticamente no meio digital para que a web venha a se tornar um espaço público que permita a comunicação cidadã; (ii) consolidar-se o movimento internacional para se firmar um contrato de princípios da Internet; (iii) contribuir para aprimorar a experiência tanto dos comunicadores quanto a fruição dos interlocutores, entre outras práticas jornalísticos referidas, como os que envolvem experimentação e artes. O sugere que, com os casos empíricos referidos, possa-se valer de diferentes possibilidades de relações comunicativas, com diferentes vieses, para fazer frente aos desafios do contexto dos novos tempos tecnológicos em que a dimensão sensível se destaca nas práticas jornalísticas experienciais. 


\section{REFERÊNCIAS}

ADAM, G. S. Notes Towards a Definition of Journalism. In: ADAM, G.S.; CLARK, R. P. (Ed.). Journalism: the democratic craft. New York: Oxford University Press, 2006, p. 344-367.

BLAIR, C. Experiential Journalism: how Virtual Reality could depict news in 3D. American Journalism Review, Dec. 10, 2014. Disponível em: https://ajr.org/2014/12/10/experientialjournalism-virtual-reality-depict-news-3d/. Acesso em: 09 nov. 2021.

CAETANO, K. L'intelligible et le sensible dans le processus de conversion de l'information journalistique en experiénce visuelle. In: XI Congres Statutaire de l'Association Internationale de Semiotique Visuelle, Liège: Université de Liège, 2015.

CAETANO, K.; FISCHER, S. Comunicação, semiótica: parcerias e percursos de uma prática epistemológica. In: OLIVEIRA, A. C. (Org.) Do sensível ao inteligível: duas décadas de construção do sentido. São Paulo: OJM Casa Ed., CPS Ed., Estação das Letras e Cores, 2014, p. 179-194.

CRAMEROTTI, A. Aesthetic journalism: how to inform without informing. Bristol: Intellect Books, 2009.

DeBARROS, A. Harvest of Change: Virtual Reality project is a journalism first. The Des Moines Register. Disponível em: www.desmoinesregister.com/story/money/agriculture/2014/09/17/harvestof-change-virtual-farm-virtual-reality/15785377/. Acesso em: 09 nov. 2021.

HABERMAS, J. Teoría de la acción comunicativa. Vol. II: Crítica de la razón funcionalista. Madrid: Taurus, 2003.

LANDOWSKI, E. Interações arriscadas. São Paulo: Estação das Letras e Cores, Centro de Pesquisas Sociossemióticas, 2014.

Com Greimas: interações semióticas. São Paulo: Estação das Letras e Cores, Centro de Pesquisas Sociossemióticas, 2017.

. Pasiones sin nombre: ensayos de sociosemiótica. Trad. Desiderio Blanco. Lima: Editorial de la Universidad de Lima, 2017b.

LONGHI, R. R.; CAETANO, K. Valor-experiência no contexto do jornalismo experiencial. Galaxia, São Paulo, n. 42, set.-dez. 2019, p. 82-95.

MARTÍN-BARBERO, J. De los medios a las mediaciones: Comunicación, cultura y hegemonía. $6^{\mathrm{a}}$. ed. Barcelona: Anthropos, 2010.

NETTO, C. A arte nos sonha: a música como revelação e inspiração do ser. São Paulo: Escuta, 2021.

O ESTADO DE S. PAULO. Expedição Antártida. O Estado de São Paulo. Disponível em: https://arte.estadao.com.br/sustentabilidade/antartida/comandante-ferraz/expedicao/. Acesso em 09 nov. 2021.

PAVLIK, J. V. The rise of virtuality: transforming cyberjournalism though experiential journalism. In: VII Congresso Internacional de Ciberjournalismo. Campo Grande, 2016.

. Education: enabling learning through immersive, interactive, customizable, and multisensorial digital platforms. Ubiquitous Learning: An International Journal. Vol. 10 Issue 1, 2017, p. $15-22$.

. Experiential media and transforming storytelling: A theoretical analysis. The journal of creative industries and cultural studies, 3, 2019a, p. 46-67.

. Journalism in the age of virtual reality: How experiential media are transforming news. New York: Columbia University Press, 2019 b. 
POSTEMA, S.; DEUZE, M. Artistic journalism: confluence in forms, values and practices, Journalism Studies, 25 Mar 2020. Disponível em: DOI: 10.1080/1461670X.2020.1745666. Acesso em 09 nov. 2021.

RANCIÈRE, J. Aisthesis: cenas do regime estético da arte. São Paulo: Editora 34, 2021.

THE NEW YORK TIMES. The Learning Network. Disponível em: https://messaging-customnewsletters.nytimes.com/template/oakv2?uri=nyt://newsletter/546fca4b-bf12-5eae-9e2e-

8080a8411 cdf\&te $=1 \& \mathrm{nl}=$ the-learning-network\&emc=edit_ln_20211018. Acesso em 18 out. 2021.

UHRY, R. Comunicação na sociedade: perspectiva panorâmica. Middletown, USA: Independently publ. KDP Amazon, 2021.

UHRY, R.; CAETANO, K. Possibilities to reinvent digital journalism to face the challenges of the new technological times, Communication and Linguistics Studies. Vol. 7, No. 3, 2021, pp. 49-56. doi: 10.11648/j.cls.20210703.12.

WRIGHT, P.; KROLL, M. J.; PARNELL, J. Administração estratégica: conceitos. São Paulo: Atlas, 2000 .

YOUTUBE. Oculus Rift DK2: Harvest of Change. Disponível em: https://www.youtube.com/watch?v=aFldP5Ze0aU. Acesso em 09 nov. 2021. 